Section Editors

David C. Spencer, MD

Steven Karceski, MD

Liu Lin Thio, MD, PhD

\title{
Childhood absence epilepsy
}

\section{Poor attention is more than seizures}

WHAT DID THE AUTHORS STUDY? Dr. Masur and colleagues ${ }^{1}$ from the Childhood Absence Epilepsy Study Group tried to answer a few important questions regarding childhood absence epilepsy (CAE) in their article "Pretreatment cognitive deficits and medication impact on attention in childhood absence epilepsy." First, they wanted to know whether children with absence epilepsy have any problems with thinking before starting medications. If the children have problems with thinking, the authors wanted to identify the specific types of thinking problems the children have. The authors also wanted to assess what effect seizure medications have on attention in these children. In principle, medications could improve or worsen attention. The possible effects of medication on attention may or may not depend on whether the medications control the seizures.

WHAT WAS KNOWN BEFORE THIS STUDY? Although many children with epilepsy have trouble with their thinking skills, the belief was that children with CAE do not. Research over the past 15 years indicates that this belief was wrong. However, these studies were small. They also did not determine whether these problems with thinking existed before starting medication or whether seizure medications helped or worsened thinking problems.

HOW WAS THIS STUDY DONE? The authors studied 446 children with newly diagnosed CAE from 32 US centers. The children took a series of tests of thinking ability (neuropsychological tests) at the start of the study. The purpose was to get an overall assessment of their thinking skills and abilities. The children completed these tests before or within 1 week of starting medication. The children were then treated with one of 3 common medications: ethosuximide, lamotrigine, or valproic acid. Each child was randomly assigned to one of these 3 medications. This method of assigning treatment ensures that the results will be scientifically sound. After 16-20 weeks on one of these medications, the authors tested the children's attention again.

WHAT WERE THE RESULTS? Did children with CAE have impaired thinking skills prior to starting treatment? The answer was yes, but only in specific areas. They had normal thinking ability in most areas at the time of diagnosis. Their overall intelligence, education, learning, and memory for words and names were normal. However, some problems were seen with attention and remembering designs and pictures.

This study highlights the problems with attention that one-third of these children had before starting medication. The results also suggest that the children lose focus on a task rather than acting impulsively. Thus, the problem is really attention and does not involve the hyperactivity seen in some children with attention problems. Importantly, parents did not recognize the attention deficits in their children. The parents probably did not notice because their children were not hyperactive.

What effect did seizure medications have on attention in children with CAE? The study found that seizure medications can affect attention. Of the 3 medications examined, valproic acid was the worst. A total of $49 \%$ of children treated with valproic acid for 16-20 weeks had attention problems. In comparison, $32 \%$ of children treated with ethosuximide and $24 \%$ of children treated with lamotrigine had attention problems after 16-20 weeks. Children treated with valproic acid were less likely to show improved attention than those treated with ethosuximide or lamotrigine. Among the children with attention deficits before treatment, $26 \%$ of children treated with valproic acid improved. However, $43 \%$ of those treated with ethosuximide and $47 \%$ treated with lamotrigine also improved. These effects on attention were independent of the medication effect on seizures.

WHAT DOES THE STUDY TELL US? The study provides valuable information about CAE. It shows that children with CAE have average intellect but they are at risk for attention difficulties at the time of diagnosis. These problems are usually subtle because they are due to inattentiveness rather than hyperactive behavior. Thus, neurologists and parents must watch carefully for attention problems that may affect performance in school and other activities.

The study provides further guidance on which medication to use first to treat CAE. A prior landmark study from the Childhood Absence Epilepsy Study Group showed that ethosuximide and valproic acid are equally good at stopping absence seizures. ${ }^{2,3}$ Lamotrigine is not as good at stopping absence seizures as ethosuximide and valproic acid. However, ethosuximide does not make attention worse. So, ethosuximide is the best of these 3 medications for treating CAE. 
WHERE DO WE GO FROM HERE? Although this study furthers our understanding of CAE, it also raises several important questions. It highlights how poorly we understand the effect of epilepsy on brain function. Why do children with CAE have attention difficulties? Why are these difficulties present at the time of diagnosis? Why can the problems continue even if a child is seizure-free? Why does valproic acid seem to worsen attention? What happens to the attention problems as the children age?

Other questions are more practical. How will neurologists identify attention problems in CAE without using a complicated test? Finally, this study stresses the need for better treatments for CAE. Current medications are not always effective and may worsen attention and thinking.

\section{REFERENCES}

1. Masur D, Shinnar S, Cnaan A, et al. Pretreatment cognitive deficits and medication impact on attention in childhood absence epilepsy. Neurology 2013;81:1572-1580.

2. Glauser TA, Cnaan A, Shinnar S, et al. Ethosuximide, valproic acid, and lamotrigine in childhood absence epilepsy. N Engl J Med 2010;362:790-799.

3. Glauser TA, Cnaan A, Shinnar S, et al. Ethosuximide, valproic acid, and lamotrigine in childhood absence epilepsy: initial monotherapy outcomes at 12 months. Epilepsia 2013;54:141-155. 
WHAT ARE SEIZURES AND WHAT IS EPILEPSY? In general, seizures are caused by abnormal electrical activity in the brain. The brain works because neurons, a type of brain cell, communicate by "firing" electrical signals. Seizures occur when neurons fire abnormal electrical signals. The symptoms of a seizure depend on where in the brain the abnormal electrical activity occurs. If it occurs in the part of the brain that controls the arm, then jerking of the arm may occur. If neurons controlling consciousness fire abnormally, the resulting seizure may cause unresponsiveness. The term "epilepsy" simply means that a person has had 2 or more unprovoked seizures.

WHAT IS CHILDHOOD ABSENCE EPILEPSY? CAE is a common type of childhood epilepsy. It accounts for about $10 \%$ of all childhood epilepsy and affects girls more frequently than boys. The main feature is absence seizures beginning in childhood, as the name indicates. Absence seizures are brief periods of unresponsiveness that start and stop abruptly. The symptoms include unresponsiveness, loss of awareness, or memory loss. Other seizure symptoms include staring, stopping ongoing activity, eye blinking, and "automatisms." Automatisms are semicoordinated repeated movements such as swallowing or wringing of the hands. The seizures last from a few seconds to as long as a minute. They often occur many times per day.

CAE usually begins between ages 4 and 10 years, most often between 5 and 7 years. Usually these children are otherwise normal. An EEG ("brain wave") test shows a specific pattern that helps confirm the diagnosis. This pattern is called generalized $3-\mathrm{Hz}$ spike and slow wave complexes. Thus, absence seizures are generalized rather than focal. In generalized seizures, brain cells on both sides of the brain fire abnormally. In focal seizures, brain cells begin firing abnormally on one side of the brain. CAE must be distinguished from other causes of staring spells such as daydreaming and some types of focal seizures.

WHAT CAUSES CHILDHOOD ABSENCE EPILEPSY? Genetic defects likely cause CAE. A few gene mutations that cause $\mathrm{CAE}$ and some gene variations that may increase the risk for this syndrome are known. However, the genetic basis for most cases is unknown. Some of the large ongoing genetic studies of epilepsy should help to identify the major genetic causes of CAE in the next few years.

HOW IS CHILDHOOD ABSENCE EPILEPSY DIAGNOSED? CAE is relatively easy to diagnose. The physician will first ask the child's parents about the spells in question and then review the child's medical history. Next, the physician performs an examination, which likely will be normal. The examination includes a few minutes of hyperventilation, which often will trigger an absence seizure in children with this diagnosis. A brain wave test (EEG) showing the typical pattern for CAE (generalized 3-Hz spike and slow wave complexes) will confirm the diagnosis. The diagnosis does not require a brain scan such as a head MRI study.

HOW IS CHILDHOOD ABSENCE EPILEPSY TREATED? Currently, treatment consists of taking a medication daily to stop the absence seizures. Several medications are available for treating CAE, including ethosuximide, valproate, and lamotrigine. Ethosuximide is the first choice because it is effective and less likely to cause side effects than some others. However, ethosuximide only works well about half of the time. Better treatments are needed. Cures or preventive treatments are desirable but are not yet available.

WHAT IS THE OUTLOOK FOR CHILDHOOD ABSENCE EPILEPSY? The outlook varies. Absence seizures go away by themselves in at least half of children by the time they become teenagers. About $40 \%$ of children may have a larger generalized tonic-clonic (formerly called "grand mal") seizure. These can occur after the absence seizures have gone away. If generalized tonic-clonic seizures appear, treatment typically requires medications other than ethosuximide.

\section{FOR MORE INFORMATION}

AAN Patients and Caregivers site

http://patients.aan.com

Epilepsy.com
http://www.epilepsy.com

Epilepsy Foundation

http://www.epilepsyfoundation.org

Medline Plus

http://www.nlm.nih.gov/medlineplus 


\title{
Neurology
}

\author{
Childhood absence epilepsy: Poor attention is more than seizures \\ Liu Lin Thio \\ Neurology 2013;81;e138-e139 \\ DOI 10.1212/01.wnl.0000436060.67147.25
}

This information is current as of October 28, 2013

$\begin{array}{ll}\begin{array}{l}\text { Updated Information \& } \\ \text { Services }\end{array} & \begin{array}{l}\text { including high resolution figures, can be found at: } \\ \text { http://n.neurology.org/content/81/18/e138.full }\end{array} \\ \text { References } & \text { This article cites } 3 \text { articles, } 1 \text { of which you can access for free at: } \\ \text { http://n.neurology.org/content/81/18/e138.full\#ref-list-1 } & \text { This article, along with others on similar topics, appears in the } \\ \text { following collection(s): } \\ \text { Absence seizures } \\ \text { http://n.neurology.org/cgi/collection/absence_seizures } \\ \text { All Epilepsy/Seizures } \\ \text { http://n.neurology.org/cgi/collection/all_epilepsy_seizures } \\ \text { All Pediatric } \\ \text { http://n.neurology.org/cgi/collection/all_pediatric } \\ \text { Information about reproducing this article in parts (figures,tables) or in } \\ \text { its entirety can be found online at: } \\ \text { http://www.neurology.org/about/about_the_journal\#permissions } \\ \text { Information about ordering reprints can be found online: } \\ \text { Pttp://n.neurology.org/subscribers/advertise }\end{array}$

Neurology ${ }^{\circledR}$ is the official journal of the American Academy of Neurology. Published continuously since 1951, it is now a weekly with 48 issues per year. Copyright (C 2013 American Academy of Neurology. All rights reserved. Print ISSN: 0028-3878. Online ISSN: 1526-632X.

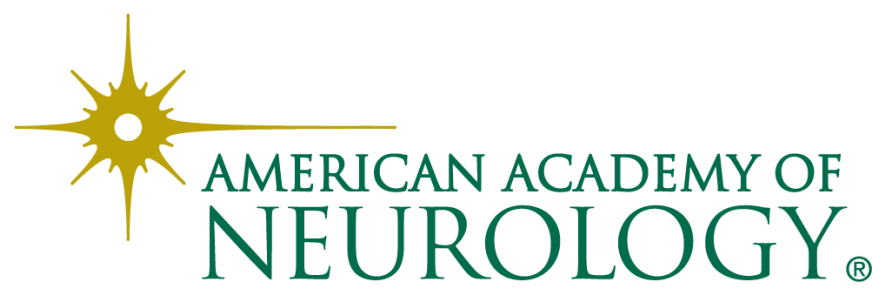

